\title{
Dietary Intake of Infant and Young Children and Assessment of Dietary Adequacy Indicators in a Pastoral Setting, Southern Ethiopia
}

This article was published in the following Dove Press journal:

Nutrition and Dietary Supplements

\section{Bekele Megersa}

Faculty of Veterinary Medicine, College of Computational and Natural Science, Hawassa University, Hawassa, Ethiopia
Correspondence: Bekele Megersa Faculty of Veterinary Medicine, College of Computational and Natural Science, Hawassa University, Hawassa, Ethiopia Email bekelebati@gmail.com
Introduction: Pastoral system is undergoing rapid socioeconomic transformation and livelihood shifts that may facilitate dietary transitions. Understanding the feeding practices and dietary intake is vitally important for designing an intervention program that addresses the nutrition needs of children in pastoral areas where scarcity of dietary information exists. Methods: Community-based study of dietary intake and questionnaire survey was conducted in Borana pastoral system of southern Ethiopia. The study aimed at investigating the dietary intake of under-five children $(\mathrm{n}=538)$ and to assess how well dietary diversity score (DDS), milk and meal frequencies estimate the adequacy of nutrient intake under pastoral context. Recipes and ingredients used to prepare the foods were recorded, and the portion size was estimated to calculate the nutrient contents per 100 grams of the food items. Then, nutrient adequacy ratio (NAR) of a given nutrient and mean adequacy ratio (MAR) were calculated.

Results: The study showed that children had a low level of DDS (2.7) and meal frequency (2.3), but had satisfactory milk frequency (4.3). About $31.2 \%$ of the children had met minimum meal frequency while only a few (11.7\%) attained the minimum DDS. Dairy $(99.8 \%)$ was the most consumed food item followed by cereals (83.6\%) and legumes (53.5\%). Thus, dairy contributed to a higher percentage $(>85 \%)$ of calcium, vitamin A and Vitamin B2 requirements. Dairy marketing was found to have significant effects on dietary patterns i.e. has reduced milk frequency but associated with an increased number of meals per day. Overall, inadequate intakes (NAR $<66 \%$ ) were observed for Vitamins A, B1, C, folic acid, and Iron. Assessment of dietary adequacy indicators showed that DDS had a greater ROC area $(0.71)$ and better prediction of dietary quality than meal $(0.62)$ and milk $(0.50)$ frequencies, but did not differ from the average of milk and meal frequencies (0.64).

Discussion: Diets of the study children were much below the WHO standards with dairy and cereals being the major component of child nutrition reflecting a typically low dietary diversity in pastoral areas. As a result, study subjects had insufficient intakes of several nutrients, implying the need for supplementing critical micronutrients. As dairy is the main staple and local commodity its marketing was found to significantly influence the dietary patterns of children. DDS was found to be the best indicator of dietary adequacy while the averaged frequencies of milk and meal also showed a promising result.

Keywords: children, dairy, dietary diversity, adequacy indicators: nutrients, pastoral

\section{Introduction}

Information on feeding practices and dietary intake is vitally important for designing required intervention measures that address the nutrition needs of children in pastoral areas where scarcity of nutrition information exists. Generally, dairy products are the 
major animal source foods in pastoral systems that substantially contribute to child nutrition. In addition to being a good source of energy and protein, milk provides several micronutrients and bioactive substances with growthpromoting abilities. ${ }^{1,2}$ As pastoralists have limited access to a variety of food sources due to the unsuitability of the environment for vegetable and fruit production and prevailing climatic variability, they are largely dependent on milk and cereal consumption. ${ }^{3-5}$ Dairy is thus a key food item that fulfills the nutritional requirements of pastoral children and contributes to their linear growth and health status. Studies also show that adequate milk intake improves nutritional status, cognitive functions and anthropometric measurements of children. ${ }^{6-8}$

Recent accounts show that the Borana pastoral system is undergoing a rapid socio-economic transformation that results in livelihood shifts towards agro-pastoral or settled farming and involvement in non-pastoral incomegenerating activities as a means of poverty alleviation or in response to increased climate variability and recurrent droughts. $^{9-11}$ Additionally, the tendency of trading dairy products for food grains and other consumable items may also contribute to the dietary transition towards plantdominated diets particularly among households closer to markets. ${ }^{12}$ However, the actual effects of milk selling on dietary intake, whether it is favoring or disfavoring dietary pattern in the pastoral area is not clear, and need further investigation. In general, the combined effects of these factors would speed the rate of dietary transition towards cereal-dominated stable food. Reduced dairy consumption along with consumption of cereal-dominated meals may further compromise the dietary quality and nutritional status of children. Under livelihood transitions, diets of children are not only poor in essential micronutrients and but also contain anti-nutrient factors that reduce the bioavailability of some micronutrients. Two studies that compared pastoral and settled communities have demonstrated the negative impacts of reduced milk consumption on the nutritional status of children in Kenya ${ }^{13}$ and Nigeria, ${ }^{14}$ which suggests the need for investigating dietary intake in the pastoral areas.

Measurements of dietary intake among children often rely on different proxy indicators because no single measurement tool can estimate precisely the actual nutrient intake. Among proxy measures used, dietary diversity score (DDS) of seven food groups is the one recommended to assess the nutrient intake of infants and children. ${ }^{15}$ However, the prevailing low levels of dietary diversity may constrain DDS as a measure of dietary intake for pastoral areas, where only a few food groups are consumed with dairy products. Additionally, previous studies did not consider meal and milk frequencies as proxy measures of dietary intake. In particular, since dairy is the major staple diet of pastoralists, the use of milk frequency as dietary measurement may provide an alternative proxy indicator. In this study, we explore the dietary intake of children, the contribution of dairy to nutrient intake and assess three proxy indicators (DDS, milk and meal frequencies) in Borana of southern Ethiopia.

\section{Methodology \\ Study Design and Samplings}

A community-based study of dietary intake and questionnaire survey was conducted in Borana pastoral system of southern Ethiopia between August and October 2015. Additionally, repeated measurements of dietary diversity, milk intakes and market prices of food items were also conducted for subsample households $(n=60)$ between August 2015 and March 2016. A total of six pastoral associations (PAs), the lowest administrative units, were randomly selected from 18 PAs in Yabello district. Following study site selection and pretest of the questionnaire in August 2015, a cluster sampling method was used to sample all eligible households from selected villages who had at least one child within the age range of 6 to 59 months. Every mother of a selected household and her one or more children were recruited for the study.

The sample size was estimated using a presumed population proportion of minimum meal frequency (42\%) report of the Ethiopian demographic and health survey, ${ }^{16}$ $95 \%$ confidence level, the marginal error of $5 \%$ and design effect (1.5 times), which gives a total of 561 subjects. We stratified the sample size into two major livelihoods as $70 \%$ cattle and $30 \%$ camel herding based on their proportion. Subsequently, a total of 538 children (6-59 months) with complete information were sampled.

\section{Data Collection}

Questionnaire survey was used to record socioeconomic variables, household characteristics (family size, education, polygamy, economic variables), maternal characteristics (age, number of children ever born, education and autonomy in decision-making) and child characteristics (age, sex, birth order, place of delivery), child feeding practices, child health care and illness history, access to 
safe water and sanitary facilities. Dietary data were collected on each day of the week by three experienced data collectors with a diploma in clinical nursing.

Dietary data such as dietary intake (amount and dietary diversity), dairy consumption (amount and frequency) and meal frequency were collected using $24 \mathrm{hrs}$ dietary recalls. Mothers or other primary caretakers of children were interviewed to assess dietary diversity according to the seven food group model of the WHO guidelines. ${ }^{15}$ Mothers or primary caregivers were asked to provide information on the frequency and duration of breastfeeding. They were also asked to list and qualitatively describe all the food items consumed by their children during the previous $24 \mathrm{hrs}$. Then, the actual food samples either purchased from local food vendors or collected from villagers (with payment compensation) were weighed using SF-400 kitchen scale. Before weighing, each mother was requested to estimate the amount consumed or portion size of a specific food item and dairy she fed to her child during each meal session. Additionally, collections of monthly data on dietary diversity and milk consumption (September 2015 to March 2016), and weekly market prices of milk, maize and beans (August 2015 to March 2016) have been performed for 10\% samples.

\section{Estimation of Nutrient Intakes}

Briefly, the nutrient contents per $100 \mathrm{~g}$ of the food items and recipes were calculated using the Food Composition Table of Ethiopia $^{17,18}$ and Nutrisurvey2007 software. The energy and nutrient intake of children were compared with the recommended nutrient intake (RNI) according to the Food and Agriculture Organization of the United Nations. ${ }^{19,20}$ The nutrient intakes of breastfed children were calculated separately according to average breast milk intake (equivalent to $533 \mathrm{~mL}$ per day) and composition as described by Dewey and Brown. ${ }^{21}$ Nutrient adequacy ratio (NAR) of a given nutrient was estimated as a ratio of the actual intake of the nutrient per day to recommended nutrient intake by sex and age group. Nutrient intakes were assessed as inadequate intake if NAR $<66 \%$, (2) fairly adequate intake (NAR: $66 \%$ to $<100 \%$ ), and adequate intake for NAR $\geq 100 \%{ }^{22}$ The mean adequacy ratio (MAR) was calculated as the sum of all NARs divided by the number of nutrients by truncating NAR of each nutrient at $100 \%{ }^{23}$ Then, the median of nutrient adequacy ratio (NAR) was calculated and used as a composite indicator for micronutrient adequacy (cutoff point) to evaluate the proxy indicators. Accordingly, the considered indicators, milk frequency, meal frequency, and their averages were compared with the dietary diversity score.

\section{Data Analysis}

Different socio-economic variables, dietary diversity score meal frequency, milk frequency were descriptively summarized as a proportion or mean. Wilcoxon ranksum test was used to assess the effects of dairy marketing practices on dietary intakes (DDS, milk and meal frequencies) of the study children. The nutrient adequacy ratio of consumed food items was summarized by selected nutrients. The relative contribution of dairy to energy and each micro-nutrient intake was estimated. The dietary intake indicators were plotted with mean nutrient adequacy ratio (MAR) using Lowess curve. The receiver operating characteristic curve (ROC) was used to assess the sensitivity and specificity of the three indicators in estimating the median nutrient adequacy ratio (at $70 \%$ cutoff point). The equality of ROC areas of milk and meal frequencies, and their averages were compared with DDS as "gold standard" using Stata software version 14.2 (College Station, TX, USA).

\section{Ethical Considerations}

Following the submission of proposal and questionnaire formats, the study was approved by the Ethical Committee of the Health Bureau of South Regional Sate. Permission was also received from the Borana zone health department. Informed verbal consent was obtained from each mother or caretaker of children after informing them about the purpose, benefit, and confidentiality of the information. Participants were told that their participation in the study is voluntary and that they can withdraw at any time; they were given the opportunity to ask study-related questions. Thus, this study was conducted in accordance with the declaration of Helsinki.

\section{Results}

Table 1 presents a summary of socioeconomic variables and characteristics of study children. About $62 \%$ of the households were Borana (cattle based livelihood) and the remaining proportion was Gabra who rely on camel production. Households had an average family size of seven individuals, and $11 \%$ of them were polygamous. Besides livestock production, households also engaged in crop cultivation (88\%) and non-pastoral activities (25\%). A significant percent of the households had a toilet $(62 \%)$, at least a mobile phone $(66 \%)$ and a radio $(35 \%)$ per family. Households need to walk on average over an hour to nearby health institutions and water points, 
Table I Socio-Economic Variables, Mother and Child Characteristics

\begin{tabular}{|c|c|}
\hline Description of Variables & $\ddagger$ Percent (\%)/Average \\
\hline \multicolumn{2}{|l|}{ Child and mother characteristics } \\
\hline Age of children in months & 32.7 \\
\hline Child sex: $($ female $=0$, male $=I)$ & 50.2 \\
\hline Exclusive breastfeeding (no $=0$, yes $=I$ ) & 29.1 \\
\hline Complementary foods (6-8MON) & 44.0 \\
\hline Mother age (years) & 29.4 \\
\hline Mother education: $($ no $=0$, yes $=I)$ & 12.5 \\
\hline Polygamy: $($ no $=0$, yes $=1)$ & 10.0 \\
\hline Decision-making: $($ no $=0$, yes $=1$ ) & 17.6 \\
\hline Number of children ever born & 4.6 \\
\hline \multicolumn{2}{|l|}{ Household characteristics } \\
\hline Ethnic: $($ Gabra=0, Borana=I) & 61.7 \\
\hline Family size & 6.6 \\
\hline Lactating animals in TLU & 2.5 \\
\hline Chicken rearing: $($ no $=0$, yes $=I)$ & 50.3 \\
\hline Number of livestock species & 3.4 \\
\hline Milk selling: $(\mathrm{no}=0$, yes $=\mathrm{I})$ & 39.2 \\
\hline Off-farm incomes: $($ no $=0$, yes $=1)$ & 24.7 \\
\hline Crop cultivation: $($ no $=0$, yes $=1$ ) & 87.9 \\
\hline Own toilet: $(\mathrm{no}=0$, yes $=1)$ & 61.9 \\
\hline Own radio: $($ no $=0$, yes $=1)$ & 35.3 \\
\hline Own mobile: $($ no $=0$, yes $=1)$ & 66.7 \\
\hline
\end{tabular}

Note: $\ddagger$ Percent is for category I; quantitative variables were averaged. TLU tropical livestock unit equivalent to $250 \mathrm{~kg}$. and about $2 \mathrm{hrs}$ or more to the closest market. The average age of mothers or caretakers was 29 years (19-65), they had a low level of literacy (12\%) and meager participation in decision-making on household resources (18\%). Mothers gave birth to five children on average, of which $30 \%$ were $<5$. Most of the mothers $(83 \%)$ were visited by health extension agents and received advice on general hygienic and sanitary practices as well as child feeding practices.

The study children consist of 270 boys and 268 girls with an average age of 32.7 months. About $86 \%$ of children aged 6-23 months were breastfeeding and $29.3 \%$ of them had exclusive breastfeeding until 6 months of age. A few children (1\%) started complementary foods at 6 months of age and $44 \%$ of them received complementary foods from 6 to 8 months while others started at later ages. Most of the children were vaccinated (97\%) and received vitamin A supplement (88\%) prior to the survey.

Table 2 presents summary of consumed dairy products and various meal preparations. Most of the children consumed fresh milk (43\%) and boiled (53\%), while few of them (3.8\%) fed fermented milk. Considerable proportion of children especially above 12 months of age consumed milk-tea (22\%) which is assumed to contain anti-nutrient factor that may interfere with absorption of calcium and

Table 2 Types Dairy Products and Food Preparations That Consumed by Children During Meal Sessions

\begin{tabular}{|c|c|c|c|}
\hline Local Name of Main Dish & English Description & Frequency & Percent \\
\hline \multicolumn{4}{|l|}{ Dairy products } \\
\hline Fresh & Milk of cattle, camel and goats & 989 & 42.7 \\
\hline Boiled & Milk boiled as whole or with tea & 1239 & 53.5 \\
\hline Fermented & Fermented milk from cows and camels & 87 & 3.8 \\
\hline Subtotal & & 2315 & \\
\hline \multicolumn{4}{|l|}{ Non-dairy food items } \\
\hline Badala & Cracked maize cooked with beans or meat, vegetables & 621 & 49.4 \\
\hline Kinche & Cracked wheat preparation with butter or oil & 63 & 5.0 \\
\hline Ruz & Rice with sauce & 80 & 6.4 \\
\hline Dinich & Boiled Irish potato & 36 & 2.9 \\
\hline Genfo, merka & Porridge mainly from maize flour & 216 & 17.2 \\
\hline Chapati & Flat bread mainly from wheat with butter or oil or sauce & 90 & 7.2 \\
\hline Kita & Flat bread from wheat or maize & 38 & 3.0 \\
\hline Chachabsa & Torn flat bread into pieces, mixed with butter, oil, spice & 16 & 1.3 \\
\hline Injera & Thin pancake from Teff with beans or meat, vegetable sauce & 20 & 1.6 \\
\hline Pasta & Pasta with sauce & 30 & 2.4 \\
\hline Kudura & Fruits & 10 & 0.8 \\
\hline Chunfa & Fresh juice from fruits & 8 & 0.6 \\
\hline Bupa & Boiled or fried eggs & 28 & 2.2 \\
\hline Biscuits & Packed biscuits in 45 to $75 \mathrm{gram}$ & 14 & 1.1 \\
\hline Subtotal & & 1256 & \\
\hline
\end{tabular}




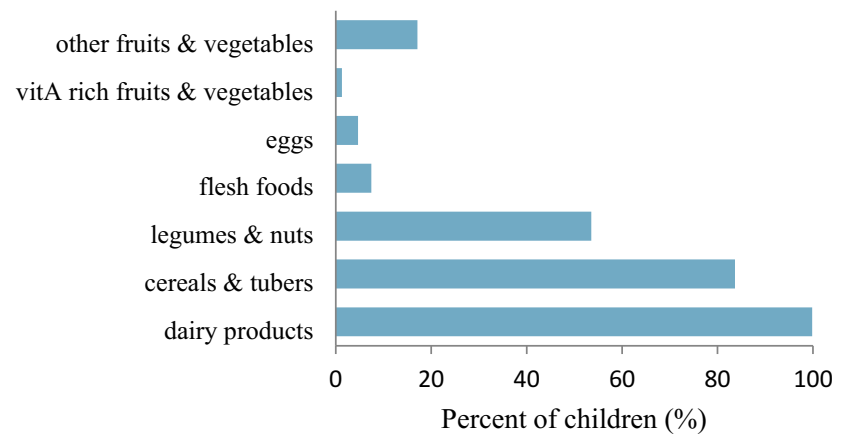

Figure I Percent of study subjects by food group consumption.

iron. The most commonly consumed local food preparations were Badala (49.4\%) followed by porridge (17.2\%), chapatti (7.2\%), rice (6.4\%), kinche $(5 \%)$, and kita (3\%). Additionally, about $7 \%$ and $18 \%$ of the children ate different foods prepared with meat and vegetables.

Figure 1 presents percent of study children by seven food group consumption. Dairy was consumed by nearly all children (99.8\%) across the age groups while consumption of cereals $(83.6 \%)$ and legumes $(53.5 \%)$ have increased with age groups. But a few children consumed animal source foods other than dairy such as meat (7.4\%) and eggs (4.5\%) while none of them ate fish or chicken. Vitamin A-rich fruits and vegetables were the least consumed food groups. Considerable proportion (34.8\%) of the children had the lowest dietary diversity intake (1-2 food groups). About half of the children (53.5\%) consumed 3 food groups while few of them (11.7\%) ate a relatively more diverse diet (4 to 5 food groups).

In general, dietary diversity was found to be very low (2.7 out of 7 food groups) and highly variable with 33\% coefficient of variation (CV). The average daily milk and meal frequencies were 4.3 (CV: 28\%) and 2.3 (CV: 47\%) times per day, respectively. The majority of the children $(>90 \%)$ had milk frequency of four and above, while only a few children (11.7\%) received the minimum dietary diversity of four and above food groups, and some of them $(31.2 \%)$ met the minimum meal frequency.
About $39 \%$ of the households sold about $10-50 \%$ of the milk they produce with a higher proportion (62\%) selling camel milk . Dairy marketing is mainly used to meet some financial requirements for purchasing food grains and other consumable commodities. Table 3 shows the effects of milk selling practices by households on the dietary intakes of study children. Milk selling had significantly reduced average daily milk intakes (4.2) by children when compared to those who do not sell (4.4). As a result, lower proportion of children (36.5\%) from milk-selling groups had four and above milk intake compared to their counterparts (63.4\%). But meal frequency was significantly higher for milk selling than other groups with much higher proportion of children in milkselling group (64.2\%) had three and above meals per day compared to others $(35.8 \%)$. There were no differences for DDS and average milk and meal frequencies by milk off-take. DDS and meal frequency showed an increasing trend with age of children, while daily milk consumption was decreasing.

Figure 2 shows fluctuations of DDS, and milk consumption with market prices of milk and food grains. DDS and milk intakes increased at the end of short rainy season in November and declined afterwards. Market price of milk also showed moderate seasonal fluctuation being higher during September and October and lower in November and December whereas no much variation in maize and beans. This slight increase in DDS and dairy consumption was found to coincide with decline in market prices. But as the study area received good rain during the survey period, much fluctuation could not be observed. Larger proportion of camel keepers sold milk at local and cross border markets (e.g., Moyale town, northern Kenya), while cattle milk was mainly sold locally during the wet season. The higher price fluctuation of cattle milk also reflects high variability in their seasonal production and supply.

Table 4 is a summary of nutrient adequacy ratio (NAR) in percent, and contributions of milk and other food sources to nutrient requirements. The overall mean adequacy ratio (MAR) and median of NARs were calculated

Table 3 Effects of Dairy Marketing Practices on Dietary Patterns of 538 Children

\begin{tabular}{|l|l|l|l|l|l|l|}
\hline \multirow{2}{*}{ Dietary Intake Indicators } & \multicolumn{2}{l|}{ None-Milk Selling (6 I\%) } & \multicolumn{2}{l|}{ Milk Selling (39\%) } & \multirow{2}{*}{ Z value } \\
\cline { 2 - 5 } & Mean (SD) & Median (Range) & Mean (SD) & Median (Range) & \\
\hline Dietary diversity score & $2.7(0.86)$ & $3(4)$ & $2.6(0.88)$ & $3(4)$ & 1.05 & 0.2961 \\
Milk frequency & $4.4(1.10)$ & $5(6)$ & $4.2(1.20)$ & $4(7)$ & 0.0167 \\
Meal frequency & $2.3(1.07)$ & $3(4)$ & $2.4(1.114)$ & $3(5)$ & -39 & 0.0119 \\
Average of milk-meal frequencies & $3.3(0.60)$ & $3.5(3.5)$ & $3.3(059)$ & $3(3)$ & 0.52 & 0.4507 \\
\hline
\end{tabular}

Note: SD: standard deviation was used for means and range was used with median. 

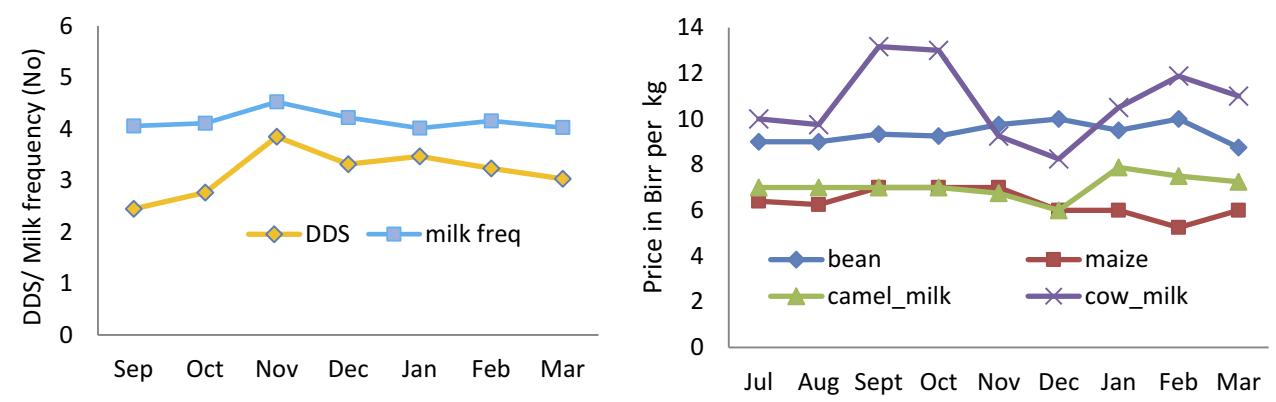

Figure 2 Relationship between milk frequency and dietary diversity and market prices of food items (plotted prices were for $0.5 \mathrm{~kg}$ milk and I kg maize and bean).

to be $66.9 \%$ (range: $21.4-96 \%$ ) and $70.6 \%$ (range: 14.5 to 100), respectively. About $10 \%$ of the children had MAR below $50 \%$ while $62 \%$ and $28 \%$ of them were between $50 \%$ and $75 \%$, and above $75 \%$, respectively. The study children had attained the required nutrient adequacy ratio (NAR) on average for protein, vitamins B2, B6 and calcium, while intake of zinc was fair. But inadequate intakes (NAR $<66 \%$ ) were observed for Vitamins A, B1, C, folic acid, and Iron. Thus, majority of the children (over $85 \%$ ) did not meet their nutrient requirements for energy, critical micronutrients including vitamins $\mathrm{A}, \mathrm{B} 1$, folic acid and $\mathrm{C}$, and iron and zinc. Dairy products had contributed substantially $(>85 \%)$ to calcium, vitamin $\mathrm{A}$ and Vitamin B2 requirements, but had the lowest content of iron, folic acid and vitamin $\mathrm{C}$.

Table 4 The Nutrient Adequacy Ratio (\%) and Contributions of Milk and Other Food Sources to Energy and Other MicroNutrient of Study Children

\begin{tabular}{|c|c|c|c|c|}
\hline \multirow[t]{2}{*}{ Nutrients } & \multicolumn{2}{|l|}{ Total } & \multirow{2}{*}{$\begin{array}{l}\text { Dairy } \\
\text { Products } \\
\text { (\%) }\end{array}$} & \multirow{2}{*}{$\begin{array}{l}\text { Other } \\
\text { Foods (\%) }\end{array}$} \\
\hline & NAR(SD) & $\begin{array}{l}\% \\
\text { Below } \\
\text { RNI }\end{array}$ & & \\
\hline Energy & $76.6(22)$ & 84 & 51.0 & 49.0 \\
\hline Protein & $113(25)$ & 39.6 & 61.4 & 38.6 \\
\hline Vitamin A & $60.1(26)$ & 92 & 87.1 & 12.8 \\
\hline Vitamin BI & $41.9(17)$ & 99.4 & 67.5 & 32.5 \\
\hline Vitamin B2 & $193.2(61)$ & 4.1 & 86.4 & 13.5 \\
\hline Vitamin B6 & $108.9(65)$ & 51.1 & 40.7 & 59.2 \\
\hline Folic acid & $48.5(25)$ & 95.5 & 23.5 & 76.5 \\
\hline Vitamin C & 22.7 (18) & 98.9 & 64.2 & 35.7 \\
\hline Calcium & $105.3(43)$ & 49.3 & 90.1 & 9.9 \\
\hline Iron & $59.6(34)$ & 86.4 & 15.7 & 84.3 \\
\hline Zinc & $76.5(31)$ & 80.5 & 52.0 & 48.0 \\
\hline MAR & 66.9 & & & \\
\hline Median & 70.6 & & & \\
\hline
\end{tabular}

Abbreviations: $\mathrm{RNI}$, recommended nutrient intake; MAR, mean nutrient adequacy ratio; NAR, nutrient adequacy ratio (\%).
Figure 3 depicts the relationship between median MAR versus individual dietary intake indicators, and their sensitivity and specificity at $70.6 \%$ cutoff point (median) of NAR. Results of individual indicators showed that DDS of four and above food groups can estimate over $80 \%$ of MAR, while four times and more daily intake of milk and meal seem to predict about $70 \%$ of the MAR. As indicated by Table 5, DDS had a significantly greater ROC area ( 0.71$)$ compared to meal (0.62) and milk (0.50) frequencies and the average of milk and meal (0.64). The sensitivity and specificity of the three indicators showed that DDS three and above provided better predictions of MAR with $80.8 \%$ sensitivity and $45.8 \%$ specificity, and $60 \%$ correct classifications compared to meal three times a day and above having $73.0 \%$ sensitivity and $47.8 \%$ specificity, and $58.0 \%$ correct classification. But milk frequency performed the lowest predication $(\mathrm{sn}=49.3 \%, \mathrm{sp}=48.9 \%$ and 49.1 correct classification) at a relatively higher frequency of four and above per day. Averaged milk and meal frequencies above three (3.5) had AUC of $64 \%$, with comparable sn=63, $\mathrm{sp}=55 \%$ and $58 \%$ correct classification compared to DDS.

\section{Discussion}

Diets of study children were characteristically dominated by high intake of dairy products in form of fresh whole milk, fermented and boiled milk, and cereal base dishes such as locally called Badala (cracked maize cooked with beans and vegetables). Accordingly, suboptimal dietary intake was observed with diets much below the WHO recommended minimum diversity and meal frequency. ${ }^{15}$ Previous studies in pastoral communities also reported low dietary diversity with dairy and cereals being the major food groups. ${ }^{3,5,24,25}$ Similarly, such low levels of dietary diversity scores have been previously reported from different parts of Ethiopia: 2.2 by Arimond and Ruel, ${ }^{26} 2.2$ by Beyene et $\mathrm{al}^{27}$ and $2.1-2.3$ by Wondafrash et al. ${ }^{28}$ Hirvonen $^{29}$ also compared dietary diversity in Ethiopia 
A

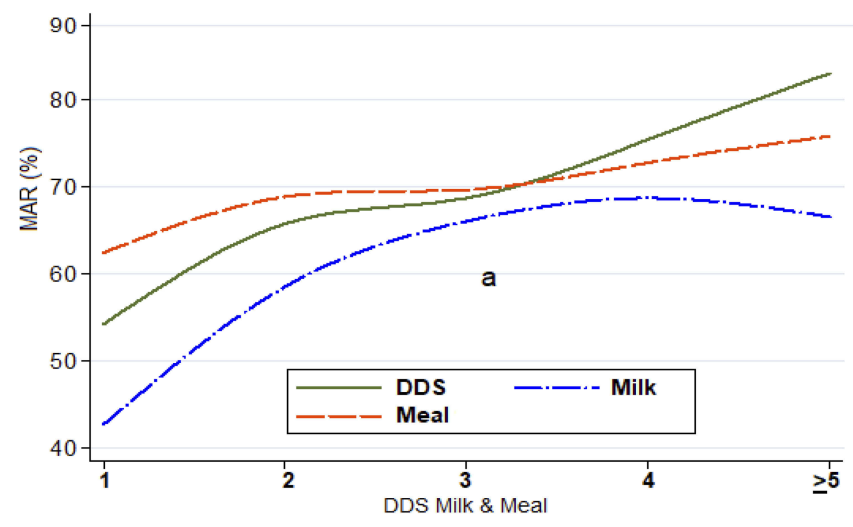

Lowess curve of DDS, milk \& meal with MAR

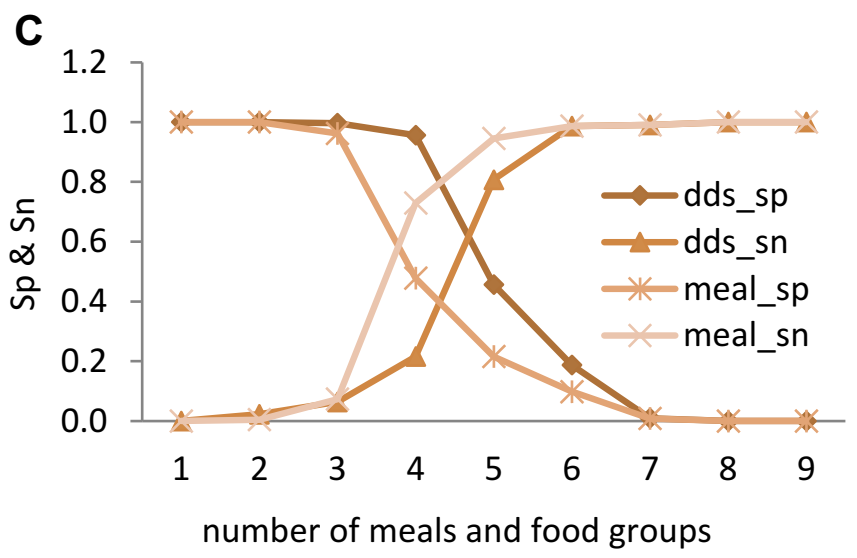

$\mathrm{Sn}$ and $\mathrm{Sp}$ of DDS with meal
B

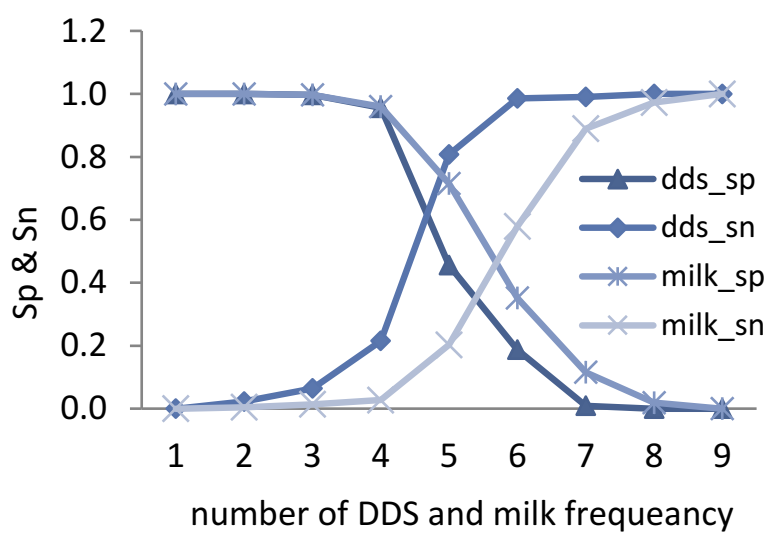

Sn and Sp of DDS with milk frequency

D

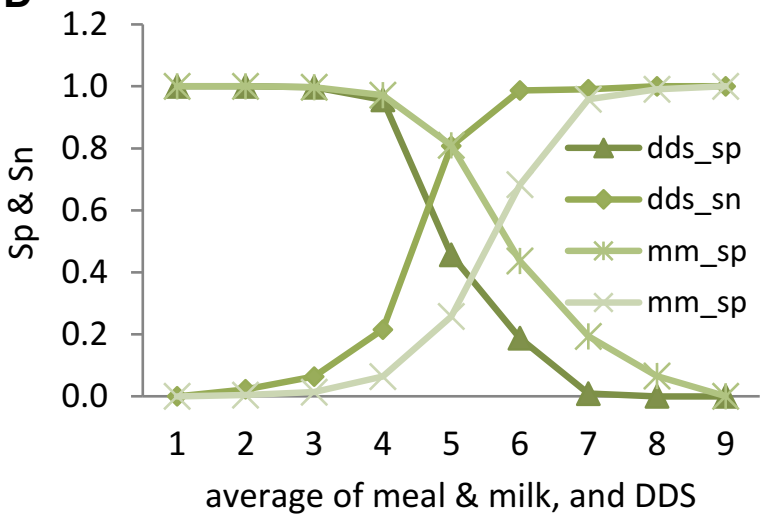

Sn and Sp of DDS with average meal-milk

Figure 3 Dietary adequacy indicators with MAR (A), and their sensitivity and specificity curves at median nutrient adequacy ratio using dietary diversity score (B-D).

with other sub-Saharan countries and found Ethiopian children to consume one of the least diverse diets in the continent, especially in rural settings. Observed low dietary diversity can be linked to the limited access of pastoralists to a variety of food groups, and the unsuitability of the arid environment for growing fruit and vegetables. Low intake of animal-source foods (non-dairy) could be explained by the fact that animals are rarely slaughtered for meat consumption (other than for ceremonial

Table 5 Comparison of the Four Indicators Using ROC Curve

\begin{tabular}{|l|l|l|l|l|l|}
\hline Dietary Indicators & AUC & SE & $\mathbf{X}^{\mathbf{2}}$ & df & Pr>chi2 \\
\hline DDS (reference) & 0.71 & 0.02 & & & \\
Milk frequency & 0.50 & 0.02 & 41.7 & 1.0 & 0.000 \\
Meal frequency & 0.62 & 0.02 & 4.8 & 1.0 & 0.035 \\
Averaged milk meal & 0.64 & 0.02 & 2.9 & 1.0 & 0.074 \\
frequency & & & & & \\
\hline
\end{tabular}

Abbreviation: AUC, area under curve. purposes), while unfamiliarity with some food items such as chicken, eggs, and unavailability of fish in the area might have reduced their consumption. Low level of formal education and awareness among mothers on the nutritional quality of foods, ${ }^{30}$ growing climatic variability (recurrent droughts) and related food insecurity ${ }^{10}$ also contribute to low dietary diversity.

Seasonal patterns of dietary diversity, dairy intake and marketing food items of sub-populations suggested some degree fluctuations with market prices of two main food items (dairy and maize). Dietary intakes found to increase at the end of the short rainy season in November, which could be regarded as harvest period when food crops such as maize and beans as well as vegetables can be consumed from their own farms. Additionally, increased milk production can be expected as the area received good rain during the study period. This also might increase the market supply of farm produce and dairy products, and subsequently, reduces the price of milk and maize as observed in November and 
December. In pastoral areas, milk for home consumption is actually prone to dry seasonal short supply and increasing off-take for cash income or trading for food grains. The closer the households to market center the more tendencies they sell milk and ultimately reduce its proportion in diets. ${ }^{12,31}$ The association of milk marketing with a reduced number of milk intakes per day and increased meal frequencies signify that households exchange dairy products of highvalue animal-source protein with starch or energy-rich cereals. This would reduce the share of dairy products (the major animal-source foods) in their diets and can compromise their dietary quality, the adverse effects of which need further investigation. Exchange of dairy products with food grains can be beneficial with sufficient supply and high exchange value. ${ }^{12}$ Accordingly, retaining the optimum amount of milk for children's consumption and seeking alternative income-generating sources would contribute to improved child nutrition in the study area. Additionally, promoting consumption of chicken and eggs is also another option that augments nutrient intake, since over half of the households were rearing backyard chickens mainly for selling eggs.

Results showed that dairy remains an integral part of the diets of the children as consumed by nearly all study subjects. Dairy contributed to higher intakes of energy, calcium, and vitamin $\mathrm{A}$, vitamin $\mathrm{B} 2$, vitamin $\mathrm{B} 1$, Zinc and protein, but found to be poor in vitamin $\mathrm{C}$ and iron contents. A similar observation was also made in Kenya where milk provided higher proportions of vitamins $\mathrm{A}, \mathrm{B} 12$, and $\mathrm{C}$ intakes by pastoral children. ${ }^{24}$ As access to diverse food sources is so limited in this study area, people largely depend on dairy consumption that partly compensates for the prevailing low dietary diversity in the area. Thus, milk can be regarded as a universal food item that can fulfill the nutritional requirements of pastoral children and ensures their linear growth and good health. Studies also show that adequate milk intake improves nutritional status, cognitive functions and anthropometric measurements of children. ${ }^{6-8}$ Besides being a good source of energy and essential micronutrients, milk provides several micronutrients and bioactive substances having growth-promoting factors that bring about taller stature. ${ }^{1,2}$ The taller and slender stature that enabled pastoralists to survive in arid environments is indeed evolved from the longterm effects of dairy intakes.

In addition to being poor sources of some essential micro-nutrients, consumed food items also contain compounds that may inhibit the absorption and bioavailability of some micronutrients. For instance, cereals such as maize meals are the most commonly consumed diet, contain phytate that may inhibit vitamin $\mathrm{A}$ or iron absorption. ${ }^{32}$ Similarly, about $22 \%$ of study children consumed milk boiled with tea, which is assumed to contain phenolic acid that may interfere with iron absorption. High consumption of dairy products, mostly cow milk contains a high level of casein, calcium and phosphorous that may interfere with non-heme iron absorption, leading to the risk for iron deficiency anemia. Thus, observed low intake of iron and vitamin C could be linked to a higher intake of cow milk, which might be a poor source of these micronutrients. Cow milk also assumed to reduce the absorption of these scarce micronutrients and worsening their bioavailability. ${ }^{33,34}$ Hence, providing supplements that are rich in iron, or ironfortified food, and promoting the intake of camel milk and consumption of locally available vitamin C-rich fruits and vegetables are recommended measures to combat the micronutrient shortfall in the study area.

Assessment of different dietary intake indicators showed that dietary diversity above three food groups provided a higher mean adequacy ratio compared to milk and meal frequencies. As a result, DDS was found to be the best predictor of dietary quality, though the average of milk and meal frequencies provided a fair estimate of mean adequacy ratio. The average of meal and milk frequencies can be considered as taking meal preparation with dairy products during meal sessions. As dietary diversity within pastoralist populations is very low, Villa et $\mathrm{al}^{5}$ defined their dietary diversity in their study as "if an individual consumed three meals of maize, one helping of beans, and two servings of milk, the dietary diversity count would be three". With this analogy, the average of meal and milk above three frequencies may be equivalent to the consumption of at least three cereals, one bean meal, and two or three dairy products per day. This can be considered as a simple tool to estimate the average dietary intake for pastoral areas such as during quick dietary surveys.

The limitation of frequency-based indicators is that they do not show the extent of dietary diversity (i.e. the same food group can be frequently consumed) or intake of nutrient-dense food groups such as animal-source foods that substantially contribute to dietary quality. Increase frequency also does not necessarily indicate an increase in quantity, when a small amount of a food item consumed at a time such as in the case of infants and young children below 2 years. For instance, infants had the highest frequency of dairy intake with likely intake of small quantities at a time. In general, DDS is still the best proxy indicator of dietary intake, even for pastoral settings 
where food variety is so limited. This observation also supports reports of previous studies in which dietary diversity score has been reported as good dietary quality indicators in different areas. ${ }^{28,35,36}$

\section{Conclusion}

The study results demonstrate that the diets of the study children were less diverse and much below the WHO standards. Dairy remains an integral part of children's diets and contributed to a higher proportion of energy, protein, and other micronutrients. Apart from being the main staple food, dairy products are the alternative local commodity that can be exchanged with food grains, which explain the significant influence of dairy marketing on the dietary patterns of children. In general, study children had an adequate intake of protein, vitamins B2, B6, and calcium, while inadequate (NAR $<66 \%$ ) intakes of vitamin A, B1, C, folic acid, and Iron were observed. Assessment of proxy indicators revealed DDS to be the best proxy indicator of dietary intake, followed by average of milk and meal frequencies.

\section{Acknowledgment}

This study was funded by the UKAID in collaboration with Tufts University. Financial supports and contribution mothers and caretakers of study children, staffs of Yabello health centers who involved in data collection and IMMANA coordinating team deserve grateful appreciation.

\section{Funding}

A postdoctoral research fellowship funded by UKAID from the UK government.

\section{Disclosure}

The author reports no conflict of interest in this work.

\section{References}

1. Hoppe C, Mølgaard C, Michaelsen KF. Cow's milk and linear growth in industrialized and developing countries. Annu Rev Nutr. 2006; 26:131-173. doi:10.1146/annurev.nutr.26.010506.103757

2. Raikos V, Dassios T. Health-promoting properties of bioactive peptides derived from milk proteins in infant food: a review. Dairy Sci Technol. 2014;94(2):91-101. doi:10.1007/s13594-013-0152-3

3. Sadler K, Kerven C, Calo M, Manske M, Catley A. The fat and the lean: review of production and use of milk by pastoralists. Pastoralism. 2010;1(2):291-324. doi:10.3362/2041-7136.2010.016

4. Mengistu G, Moges T, Samuel A, Baye K. Energy and nutrient intake of infants and young children in pastoralist communities of Ethiopia. Nutrition. 2017;41:1-6. doi:10.1016/j.nut.2017.02.012

5. Villa KM, Barrett CB, Just DR. Whose fast and whose feast? Intra-household asymmetries in dietary diversity response among East African pastoralists. Am J Agric Econ. 2011;93:1062-1081. doi:10.1093/ajae/aar038
6. Thi D, Lien $\mathrm{K}$, Thi $\mathrm{B}$, et al. Impact of milk consumption on performance and health of primary school children in rural Vietnam. Asia Pac J Clin Nutr. 2009;18(3):326-334.

7. Rahmani K, Djazayeri A, Ibrahimhabibi M, et al. Effects of daily milk supplementation on improving the physical and mental function as well as school performance among children: results from a school feeding program. J Res Med Sci. 2011;16(4):469-476.

8. Dror DK, Allen LH. The importance of milk and other animal-source foods for children in low-income countries. Food Nutri Bull. 2011;32:227-243.

9. Desta S, Coppock DL. Pastoralism under pressure: tracking system change in Southern Ethiopia. Hum Ecol. 2004;32(4):465-486. doi:10.1023/B:HUEC.0000043516.56037.6b

10. Megersa B, Markemann A, Angassa A, Valle Zárate A. The role of livestock diversification in ensuring household food security under a changing climate in Borana, Ethiopia. Food Secur. 2014;6 (1):15-28. doi:10.1007/s12571-013-0314-4

11. Tache B, Oba G. Is poverty driving Borana Herders in Southern Ethiopia to crop cultivation? Hum Ecol. 2010;38:639-649. doi:10.1007/s10745-010-9349-8

12. Holden SJ, Coppock DL, Assefa M. Pastoral dairy marketing and household wealth interactions and their implications for calves and humans in Ethiopia. Hum Ecol. 1991;19(1):35-59. doi:10.1007/BF00888976

13. Fratkin E, Roth EA, Nathan MA. Pastoral sedentarization and its effects on children's diet, health, and growth among Rendille of Northern Kenya. Hum Ecol. 2004;32(5):531-559. doi:10.1007/s10745-004-6096-8

14. Ekpo UF, Omotayo AM, Dipeolu MA. Prevalence of malnutrition among settled pastoral Fulani children in Southwest Nigeria. BMC Res Notes. 2008;1:7. doi:10.1186/1756-0500-1-7

15. WHO. Indicators for Assessing Infant and Young Child Feeding Practices; 2010.

16. DHS. Ethiopian Demographic and Health Survey. Addis Ababa, Ethiopia: Central Statistical Agency; 2011. Available from: http:// Www.Measuredhs.Com;2011. Accessed January 23, 2020.

17. EHNI. Ethiopian Traditional Recipes. 1st ed. Addis Ababa: Ethiopian Health and Nutrition Institute (EHNI); 1980.

18. EHNRU. Food Composition Table for Use in Africa. 1968;1:2012. doi10.1016/s0022-3182(69)80022-1

19. FAO/WHO/UNU J. Human energy requirements. Scientific background papers from the Joint FAO/WHO/UNU Expert Consultation. October 17-24, 2001. Rome, Italy. Public Health Nutr. 2005;8 (7A):929-1228. doi10.1079/phn2005778

20. WHO FAO. Vitamin and mineral requirements in human nutrition, Second edition. Jt FAO/WHO Expert Consult Hum Vitam Miner Requir. 1998;1-362.

21. Dewey KG, Brown KH. Special issue based on a world health organization expert consultation on complementary feeding. Food Nutr Bull. 2003;24(1):1-141.

22. Singh A, Gupta V, Ghosh A, Lock K, Ghosh-jerath S. Quantitative estimates of dietary intake with special emphasis on snacking pattern and nutritional status of free living adults in urban slums of Delhi: impact of nutrition transition. BMC Nutri. 2015;1:1-11. doi:10.1186/ s40795-015-0018-6

23. Hatløy A, Torheim LE, Oshaug A. Food variety - a good indicator of nutritional adequacy of the diet? A case study from an urban area in Mali, West Africa. Eur J Clin Nutr. 1998;52(12):891-898. doi:10.1038/sj.ejcn.1600662

24. Iannotti L, Lesorogol C, Animal milk sustains micronutrient nutrition and child anthropometry among pastoralists in Samburu, Kenya. Am J Phys Anthropol. 2014;155(1):66-76. doi:10.1002/ajpa.v155.1

25. Lindtjørn B, Alemu T, Bjorvatn B. Dietary pattern and state of nutrition among children in drought-prone areas of southern Ethiopia. Ann Trop Paediatr. 1993;13(1):21-32. doi:10.1080/02724936.1993.11747621

26. Arimond M, Ruel MT. Dietary diversity is associated with child nutritional status: evidence from 11 demographic and health surveys. J Nutr. 2018;134(10):2579-2585. doi:10.1093/jn/134.10.2579 
27. Beyene M, Worku AG, Wassie MM. Dietary diversity, meal frequency and associated factors among infant and young children in Northwest Ethiopia: a cross-sectional study. BMC Public Health. 2015;15(1):1007. doi:10.1186/s12889-015-2333-x

28. Wondafrash M, Huybregts L, Lachat C, Bouckaert KP, Kolsteren P. Dietary diversity predicts dietary quality regardless of season in 6 12-month-old infants in south-west Ethiopia Dietary diversity score and micronutrient density. Public Health Nutr. 2016;(14):1-10. doi:10.1017/S1368980016000525

29. Hirvonen K. Rural-urban differences in children's dietary diversity in Ethiopia: a poisson decomposition analysis. Econ Lett. 2016;147:12-15. doi:10.1016/j.econlet.2016.08.003

30. Hirvonen K, Hoddinott J, Minten B, Stifel D. Children's diets, nutrition knowledge, and access to markets. World Dev. 2017;95:303-315. doi:10.1016/j.worlddev.2017.02.031

31. Kebede S, Animut, G., \& Zemedu, L. The Contribution of Camel Milk to Pastoralist Livelihoods in Ethiopia. An Economic Assessment in Somali Regional State. London; 2015. http://pubs.iied.org/ 10122IIED. Accessed January 23, 2020.
32. Onyango AW. Dietary diversity, child nutrition and health in contemporary African communities. Comp Biochem Physiol - A Mol Integr Physiol. 2003;136(1):61-69. doi:10.1016/S1095-6433(03) 00071-0

33. Oliveira MAA, Osório MM. Cow's milk consumption and iron deficiency anemia in children. $J$ Pediatr (Rio J). 2005;81(5):361-367. doi:10.2223/jped.1386

34. Ziegler EE. Consumption of cow' s milk as a cause of iron deficiency in infants and toddlers. Nutr Rev. 2011;69:37-42. doi:10.1111/ j.1753-4887.2011.00431.x

35. Torheim LE, Ouattara F, Diarra MM, et al. Nutrient adequacy and dietary diversity in rural Mali: association and determinants. Eur J Clin Nutr. 2004;58(4):594-604. doi:10.1038/sj.ejcn.1601853

36. Steyn NP, Nel JH, Nantel G, Kennedy G, Labadarios D. Food variety and dietary diversity scores in children: are they good indicators of dietary adequacy? Public Health Nutr. 2006;9(5):644-650. doi:10.10 79/PHN2005912
Nutrition and Dietary Supplements

\section{Publish your work in this journal}

Nutrition and Dietary. Supplements is an international, peerreviewed, open access journal focusing on research into nutritional requirements in health and disease, impact on metabolism and the identification and optimal use of dietary strategies and supplements necessary for normal growth and development. The journal welcomes submitted papers covering original research, basic science,

\section{Dovepress}

clinical \& epidemiological studies, reviews and evaluations, guidelines, expert opinion and commentary, case reports and extended reports. The manuscript management system is completely online and includes a very quick and fair peer-review system, which is all easy to use. Visit http://www.dovepress.com/testimonials.php to read real quotes from published authors. 